\title{
Analysis of microRNA from archived formalin-fixed paraffin-embedded specimens of amyotrophic lateral sclerosis
}

\author{
Koichi Wakabayashi ${ }^{*}$, Fumiaki Mori ${ }^{1}$, Akiyoshi Kakita ${ }^{2}$, Hitoshi Takahashi ${ }^{3}$, Jun Utsumi ${ }^{4}$ and Hidenao Sasaki ${ }^{4}$
}

\begin{abstract}
Background: MicroRNAs (miRNAs) are noncoding small RNAs that regulate gene expression. This study investigated whether formalin-fixed paraffin-embedded (FFPE) specimens from postmortem cases of neurodegenerative disorders would be suitable for miRNA profiling.

Results: Ten FFPE samples from 6 cases of amyotrophic lateral sclerosis (ALS) and 4 neurologically normal controls were selected for miRNA analysis on the basis of the following criteria for RNA quality: (i) a postmortem interval of less than 6 hours, (ii) a formalin fixation time of less than 4 weeks, (iii) an RNA yield per sample of more than 500 ng, and (iv) sufficient quality of the RNA agarose gel image. An overall RNA extraction success rate was $46.2 \%$. For ALS, a total of 364 miRNAs were identified in the motor cortex, 91 being up-regulated and 233 down-regulated. Target genes were predicted using miRNA bioinformatics software, and the data applied to ontology analysis. This indicated that one of the miRNAs up-regulated in ALS (miR-338-3p) had already been identified in leukocytes, serum, cerebrospinal fluid and frozen spinal cord from ALS patients.
\end{abstract}

Conclusion: Although analysis was possible for just under half of the specimens examined, we were able to show that informative miRNA data can be derived from archived FFPE samples from postmortem cases of neurodegenerative disorders.

Keywords: AMBRA1, Amyotrophic lateral sclerosis, Autophagy, Bioinformatics, Formalin-fixed paraffin-embedded specimen, MicroRNA

\section{Introduction}

MicroRNAs (miRNAs) are small, single-stranded, noncoding RNAs that regulate gene expression at the transcriptional and translational levels in both plants and animals [1]. A single miRNA may bind to as many as 200 target genes [2]. miRNAs are of great interest because they can regulate approximately $30 \%$ of human genes [3] and have a huge impact on a wide range of basic biological processes including developmental timing, cell death, cell proliferation, hematopoiesis and patterning of the nervous system [4]. The implications of miRNA network dysregulation have already been well demonstrated in the field of cancer research, suggesting

\footnotetext{
* Correspondence: koichi@cc.hirosaki-u.ac.jp

'Department of Neuropathology, Institute of Brain Science, Hirosaki University Graduate School of Medicine, 5 Zaifu-cho, Hirosaki 036-8562, Japan

Full list of author information is available at the end of the article
}

that miRNAs may be good biomarkers for cancer diagnosis and prognosis [5]. The role of miRNAs has also been studied in neurodegenerative conditions such as Alzheimer s disease [6-22], Parkinsons disease [19,23-27], Huntington s disease [28-30], multiple system atrophy [31] and amyotrophic lateral sclerosis (ALS) [19,32-36], postmortem frozen brain tissue having been employed in most cases [6-22,26,28,30,31]. Several investigators have also analyzed miRNAs from cerebrospinal fluid (CSF) [6,34,37], peripheral blood [33,34,37-39] and skeletal muscle [32,35].

Although the yield, quality and integrity of RNA can be reduced through cross-linking with proteins, enzyme degradation as well as chemical degradation during the fixation process [40-44], the expression of miRNAs in formalin-fixed paraffin-embedded (FFPE) samples is known to be well correlated with that in fresh frozen samples [45]. Moreover, the expression of miRNAs is preserved after routine fixation in formalin (up to 5 days) 
and long-term storage in paraffin (up to 10 years) [45]. Therefore, FFPE samples have recently been used for studies of miRNA in cancer [46-51]. However, the stability and expression of miRNAs in FFPE specimens obtained postmortem and fixed for longer time periods (weeks or months) have not been investigated.

In the present study, we isolated RNAs from archived FFPE brain specimens of postmortem cases of ALS and neurologically normal controls. Although miRNA analysis was possible for only a minority of FFPE blocks, we were able to show that informative data can be derived from selected FFPE postmortem specimens of human brain.

\section{Materials and methods \\ Subjects}

To investigate the effect of postmortem interval, formalin fixation and storage period on the stability of RNA, we selected 10 samples (Table 1) that had been obtained at autopsy from 1 to 10 hours after death. The brains from which the specimens had been obtained had been immersed in $10 \%$ or $20 \%$ formalin or $10 \%$ phosphatebuffered formalin for 316 weeks. After fixation, the cerebrum had been cut into slices $10 \mathrm{~mm}$ thick in the coronal plane. Samples had then been removed from each slice and subjected to tissue processing (dehydration, clearing and impregnation) on an automated instrument (Tissue-Tek VIP 5 Jr., Sakura Finetek Japan, Tokyo, Japan) that employed seven steps of $100 \%$ ethanol, three steps of xylene, and four steps of paraffin, with 8 hours at each step. The instrument was operated under vacuum and heated to $37 \mathrm{C}$ for the ethanol and xylene steps and $60 \mathrm{C}$ for the paraffin steps. After tissue processing, each specimen had been embedded in paraffin, and the paraffin blocks had been stored for 1086 months at room temperature protected from air and sunlight.
On the basis of the criteria reported by Osawa et al. [50], four criteria were adopted for establishing the suitability of the samples for RNA analysis: (i) a postmortem interval of less than 6 hours, (ii) a formalin fixation time of less than 4 weeks, (iii) a total RNA yield per sample of more than $500 \mathrm{ng}$, and (iv) sufficient quality of the RNA electrophoresis pattern.

We further evaluated an additional 16 samples (8 cases of ALS and 8 cases of normal controls) for which the postmortem interval had been less than 6 hours and the formalin fixation time had been less than 4 weeks. Thus, we evaluated a total of 26 samples. On this basis, 10 FFPE samples were selected for miRNA analysis, comprising 6 cases of sporadic ALS and 4 neurologically normal controls (Table 2). The FFPE specimens employed were from the motor cortex of patients with ALS and normal subjects. All the diagnoses had been confirmed by neuropathological examination using immunohistochemistry for TDP-43 and ubiquitin. This study was approved by the Institutional Ethics Committee of Hirosaki University Graduate School of Medicine, Japan.

\section{RNA extraction}

Two 5- $\mu$ m-thick sections were cut from each block and placed in sterile $1.5-\mathrm{mL}$ centrifuge tubes ready for extraction. Tubes containing cut FFPE sections for RNA purification were stored at $-80 \mathrm{C}$ until use. Total RNA including small RNAs was extracted using an Arcturus Paradise PLUS FFPE RNA Isolation Kit (Life Technologies Corporation, Carlsbad, CA, USA) with the following modifications. Paraffin was removed by xylene treatment and the tissues were washed with ethanol twice to remove the xylene. The tissues were then treated with proteinase $\mathrm{K}$ at $37 \mathrm{C}$ overnight, as proteinase $\mathrm{K}$ enables extraction of almost the same amount of RNA from FFPE specimens as from fresh frozen samples [52]. After centrifugation, the supernatant was processed with a

Table 1 Summary of fixed paraffin-embedded samples used for RNA isolation

\begin{tabular}{|c|c|c|c|c|c|c|c|}
\hline Sample no. & $\begin{array}{l}\text { Pathological } \\
\text { diagnosis }\end{array}$ & $\begin{array}{l}\text { Postmortem interval } \\
\text { (hours) }\end{array}$ & $\begin{array}{l}\text { Fixation time } \\
\text { (weeks) }\end{array}$ & Fixative & $\begin{array}{l}\text { Storage period } \\
\text { (months) }\end{array}$ & $\begin{array}{l}\text { Sample size } \\
(\mathrm{mm})\end{array}$ & $\begin{array}{l}\text { RNA yield } \\
\text { (ng) }\end{array}$ \\
\hline 1 & ALS & 1 & 4 & $20 \% \mathrm{~F}$ & 24 & $30 ? 40$ & 3198 \\
\hline 2 & ALS & 2 & 4 & $10 \%$ BF & 49 & $30 ? 40$ & 4178 \\
\hline 3 & ALS & 9 & 8 & $20 \% \mathrm{~F}$ & 56 & $30 ? 50$ & 911 \\
\hline 4 & ALS & 9 & 12 & $20 \% \mathrm{~F}$ & 10 & $30 ? 50$ & 601 \\
\hline 5 & ALS & 9 & 16 & $20 \% \mathrm{~F}$ & 86 & $25 ? 35$ & 515 \\
\hline 6 & ALS & 4 & 9 & $10 \%$ BF & 24 & $20 ? 25$ & 594 \\
\hline 7 & ALS & 4 & 10 & $10 \%$ BF & 12 & $20 ? 20$ & 251 \\
\hline 8 & Control & 4 & 4 & $10 \% \mathrm{~F}$ & 38 & $30 ? 40$ & 2769 \\
\hline 9 & Control & 10 & 3 & $10 \% \mathrm{~F}$ & 86 & $25 ? 40$ & 1414 \\
\hline 10 & Control & 10 & 4 & $10 \% \mathrm{~F}$ & 64 & $30 ? 45$ & 765 \\
\hline
\end{tabular}

ALS, amyotrophic lateral sclerosis, F, formalin, BF, buffered formalin. 
Table 2 Characteristics of postmortem cases in microRNA study

\begin{tabular}{lllllll}
\hline Case no. & $\begin{array}{l}\text { Pathological } \\
\text { diagnosis }\end{array}$ & Age/gender & $\begin{array}{l}\text { Disease duration } \\
\text { (months) }\end{array}$ & $\begin{array}{l}\text { Postmortem interval } \\
\text { (hours) }\end{array}$ & $\begin{array}{l}\text { Fixation time } \\
\text { (weeks) }\end{array}$ & $\begin{array}{l}\text { Storage period } \\
\text { (months) }\end{array}$ \\
\hline 1 & ALS & $68 / \mathrm{M}$ & 12 & 1 & 4 & 24 \\
2 & ALS & $60 / \mathrm{M}$ & 108 & 2 & 4 & 49 \\
3 & ALS & $59 / \mathrm{M}$ & 36 & 9 & 8 & 56 \\
4 & ALS & $75 / \mathrm{M}$ & 11 & 4 & 4 & 36 \\
5 & ALS & $73 / \mathrm{M}$ & 9 & 1.5 & 4 & 60 \\
6 & ALS & $72 / \mathrm{M}$ & 120 & 2 & 4 & 60 \\
7 & Control & $67 / \mathrm{F}$ & & 4 & 4 & 38 \\
8 & Control & $71 / \mathrm{F}$ & & 10 & 3 & 86 \\
9 & Control & $84 / \mathrm{M}$ & & 10 & 4 & 64 \\
10 & Control & $60 / \mathrm{F}$ & & 2 & 4 & 12 \\
\hline
\end{tabular}

silica-based spin column (Toray Industries Inc., Tokyo, Japan) in order to obtain purified total RNA. The degrees of RNA cross-linking and RNA degradation were analyzed by agarose gel electrophoresis using an Agilent 2100 Bioanalyzer (Agilent Technologies, Santa Clara, CA, USA). RNA yield was determined from the $A_{260} / A_{280}$ absorbance ratio using a NanoDrop ND-1000 spectrophotometer (Thermo Fisher Scientific, Waltham, MA, USA).

To assess the feasibility of analyzing RNA extracted from FFPE samples, we applied the selection criteria for RNA quality reported by Osawa et al. [50], as described above. The RNA electrophoresis pattern was found to be crucial for estimation of RNA quality. When the majority of RNAs were $>4000$ nucleotides (nt) in size due to cross-linking or when almost all of the RNAs were fragmented (e.g., <1000 nt), the RNA quality was considered unsuitable for miRNA analysis.

\section{miRNA expression profiling}

Extracted samples of total RNA that satisfied our criteria were labeled with Hy5 using a miRCURY LNA Array miR labeling kit (Exiqon, Vedbaek, Denmark). The labeled RNAs were then hybridized onto a 3D-Gene human miRNA oligo chip (Toray Industries Inc.). The annotation and oligonucleotide sequences of the probes conformed to the miRBase miRNA database Release 17v1.0.0 (http:// www.mirbase.org/). After stringent washing, the fluorescent signals were scanned with a 3D-Gene Scanner (Toray Industries Inc.) and analyzed using 3D-Gene Extraction software (Toray Industries Inc.).

The raw data for each spot were normalized by subtraction of the mean intensity of the background signal determined from the signal intensities of all blank spots with 95\% confidence intervals. Measurements for spots with signal intensities greater than 2 standard deviations (SD) of the background signal intensity were considered to be valid. The relative level of expression for a given miRNA was calculated by comparing the signal intensities of the valid spots throughout the microarray experiments. The normalized data were globally normalized per array, adjusting the median of the signal intensity to 25 .

Any signal intensity level over 50 was considered to be significant. The signal was considered to be up-regulated when $\log _{2} \mathrm{X}$ was increased by 0.1 or more $\left(\geqq \log _{2} \mathrm{X}=+0.1\right)$ compared with the control signal level, and downregulated when $\log _{2} \mathrm{X}$ was decreased by -0.1 or less $\left(\leqq \log _{2} \mathrm{X}=-0.1\right)$ compared with the control signal level.

\section{miRNA targets and pathway analysis}

Bioinformatics prediction of target genes and miRNA binding sites was performed using miRmap web-based open source software (http://mirmap.ezlab.org/) [53]. Canonical function and ontology analyses for candidate miRNA targets were performed using MetaCore Functional Analysis (ver.6.19, Thomson Reuter/GeneGo, http:// lsresearch.thomsonreuters.com/) which is an integrated knowledge base and pathway analysis tool based on a proprietary manually curated database of human protein protein, protein DNA and protein compound interactions, and metabolic and signaling pathways, all supported by proprietary ontologies. Gene ontology enrichment analysis was also performed with Gene Ontology Consortium (GOC) web tool (http://geneontology.org/) to confirm standard GO term on the coincidences.

\section{Immunohistochemistry}

Since SOGA1 (suppressor of glucose by autophagy) [54] was identified as one of the candidate target genes of both up-regulated and down-regulated miRNAs, we evaluated the protein expression levels of autophagy-related genes such as AMBRA1 [55], Beclin 1 [56], ULK1 [57] and ULK2 [57] using immunohistochemistry. Serial 4- $\mu \mathrm{m}-$ thick FFPE sections from the motor cortex and spinal cord (7th cervical, 8th thoracic and 4th lumbar segments) of ALS patients $(n=13)$ were employed. We also examined neurologically normal individuals (normal control) $(n=6)$ 
and patients with various neurological diseases affecting the spinal anterior horn (diseased control) $(n=6)$. Three sections $40 \mu \mathrm{m}$ apart were subjected to immunohistochemistry using the avidin-biotin-peroxidase complex method with a Vectastain ABC kit (Vector, Burlingame, CA, USA). The sections were subjected to heat retrieval using an autoclave for $10 \mathrm{~min}$ at $121 \mathrm{C}$ in $10 \mathrm{mM}$ citrate buffer ( $\mathrm{pH}$ 6.0), and then immunostained with rabbit polyclonal antibodies against AMBRA1 (NOVUS USA, Littleton, CO, USA; 1:1000), Beclin 1 (NOVUS USA; 1:200), ULK1 (Thermo Scientific, Rockford, IL, USA; 1:100) and ULK2 (Thermo Scientific; 1:500). Diaminobenzidine was used as the chromogen, and the sections were counterstained with hematoxylin.

\section{Semi-quantitative analysis}

Since AMBRA1 immunoreactivity was decreased in the spinal anterior horn cells in ALS, we assessed the number of AMBRA1-immunoreactive neurons in the spinal anterior horn of control subjects and patients with ALS using a semi-quantitative rating scale, as reported previously [58]: -, unstained; +, weakly stained; ++, moderately or intensely stained. In each case, the numbers of neurons were counted in Rexeds laminae VIII and IX of the lumbar spinal cord. Counting was performed at an original magnification of x200 using an eyepiece graticule and parallel sweeps of the microscope stage.

\section{Statistical analysis}

Calculations were performed using Statcel software (OMS Publishing, Tokorozawa, Japan). Repeated measures analysis of variance and Students or Welchs $t$ test were used to evaluate possible differences in staining intensity between normal controls, diseased controls and ALS. Values were expressed as mean standard error of the mean. Correlations at $\mathrm{p}<0.05$ were considered to be significant.

\section{Results}

Stability of RNA in postmortem samples

The RNA yield was not correlated with the period of storage of FFPE blocks. However, the RNA yield was influenced by the period of formalin fixation (Table 1), being significantly higher in samples that had been fixed for a short period (3 4 weeks; mean $2465 \mathrm{ng}$ ) than in those that have been fixed for a long period (8 16 weeks; mean $574 \mathrm{ng})(\mathrm{p}<0.05)$. The RNA yield did not appear to be affected by the type of fixative employed. Postmortem interval could be also relevant. Samples with higher RNA yield (samples 1, 2 and 8) were the cases in whom postmortem interval was within 4 hours. The rest with lower RNA yield (samples 3 7, 9 and 10) had a combination of longer postmortem interval (9 10 hours) and/or fixation (8 16 weeks). RNA integrity was checked by electrophoresis, and a representative RNA agarose gel image is shown in Figure 1. A band of 5000 nt corresponding to $28 \mathrm{~S}$ ribosomal RNA was slightly shifted toward a higher molecular weight in all cases, indicating overfixation with formalin and the presence of chemical modifications of the RNA such as covalently linked residual amino acids [59]. A band of 2000 nt corresponding to $18 \mathrm{~S}$ ribosomal RNA was seen in some cases (Figure 1), suggesting that the extracted RNA was of good quality. These bands were not only shifted, but also appeared more diffuse and less focused. The bands of 100200 nt corresponded to degraded RNA, as reported previously [60]. On the basis of these

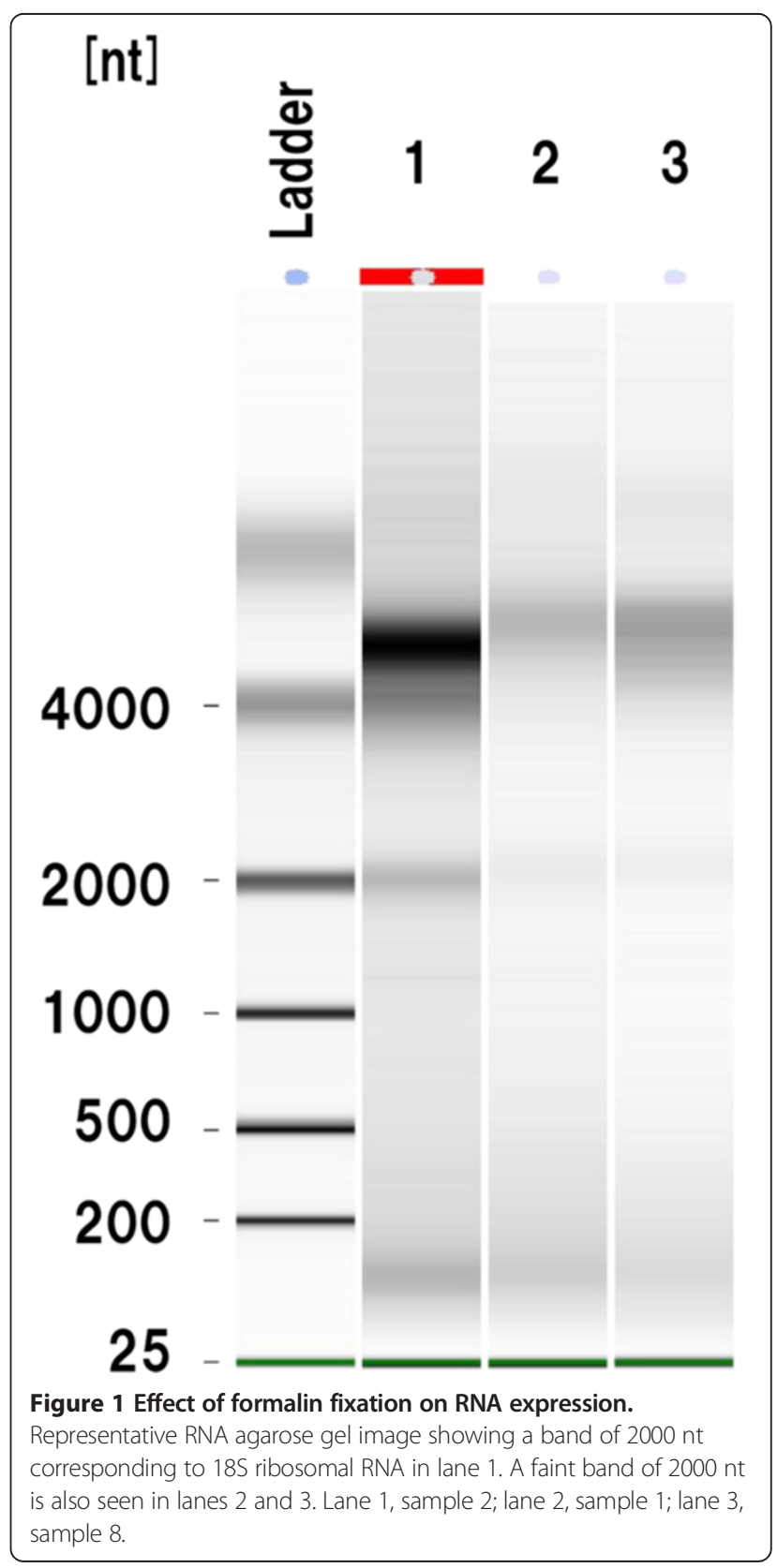


initial analyses, we adopted four criteria to indicate that RNA would be of sufficient quality for analysis, based on Osawa et al. [50]: (i) a postmortem interval of less than 6 hours, (ii) a formalin fixation time of less than 4 weeks, (iii) a total RNA yield per sample of more than $500 \mathrm{ng}$, and (iv) a RNA electrophoresis pattern of good quality.

We evaluated an additional 16 samples (8 cases of ALS and 8 cases of normal controls) for which the postmortem interval had been less than 6 hours and the formalin fixation time had been less than 4 weeks. The RNA yield was more than $500 \mathrm{ng}$ for 12 of these samples, and the RNA agarose gel image was of sufficient quality in 4 . As a result, we evaluated a total of 26 samples. The RNA yield was more than $500 \mathrm{ng}$ in 20 of the 26 samples, and the RNA agarose gel image was of sufficient quality in 12. Thus, the success rate for analysis of RNA from FFPE samples of the human postmortem brain was $46.2 \%$ (12 of 26 ).

Based on the above step, 10 cases were selected for miRNA analysis; these included cases of sporadic ALS $(n=6)$ and neurologically normal controls $(n=4)$ (Table 2$)$. In case 3 , although the fixation time had been 8 weeks, it was included in the present analysis, because the RNA yield was more than $500 \mathrm{ng}$ and the RNA agarose gel image was of sufficient quality.

\section{miRNA analysis and candidate target genes in ALS}

A total of 364 miRNAs were isolated from the motor cortex of patients with ALS. Forty miRNAs showed no change $\left(-0.1<\log _{2} \mathrm{X}<+0.1\right)$, and 91 were up-regulated $\left(\log _{2} X \geqq+0.1\right)$ and 233 were down-regulated $\left(\log _{2} X \leqq-\right.$ $0.1)$ relative to the controls. Top 20 microRNAs up- or down-regulated in ALS are shown in Additional file 1: Table S1. miR-494 was found to be the most highly differentially up-regulated miRNA (+4.99-fold change), followed in order by miR-4257, miR-24-3p, miR-4299, and miR-1973 as the top 5 up-regulated miRNAs. On the other hand, miR-4740-5p (+0.19-fold change), miR1290, miR-3619-3p, miR-1246, and miR-3180-3p were the top 5 down-regulated miRNAs.

Scatter plot of all 364 miRNAs comparing signal intensity versus $\log _{2}$ fold-change of ALS/control ratio is shown in Figure 2. We selected 6 up-regulated miRNAs (miR-494, miR-4257, miR-24-3p, miR-4299, miR-1973 and miR-4485) and 8 down-regulated miRNAs (miR4740-5p, miR-1290, miR-3619-3p, miR-1246, miR-31803p, miR-4648, miR-4716-3p and miR-663) in ALS. The candidate target genes of the 6 up-regulated and 8 down-regulated miRNAs in ALS were identified using miRmap web-based open source software.

Top 50 candidate target genes of each of the 6 upregulated miRNAs in ALS were selected according to the miRmap score. Of the 300 target candidates identified for each of the 6 miRNAs, there was an overlap of 13 genes (Additional file 2: Table S2). These 13 genes have been reported to be involved in muscular cell proliferation (FOXK1 [61], MEF2D [62]), synaptic transmission (ITSN1 [63], RAB3B [64], SLC6A5 [65]), mitochondrial regulation (IBA57 [66], PPARGC1B [67]) and autophagy (MEF2D [68], SOGA1 [54]). These genes may be downregulated by the 6 up-regulated miRNAs in affected brain regions of ALS. In addition, miR-24-3p showed the most matching frequency (7 overlapped in 50 targets) in upregulated miRNAs.

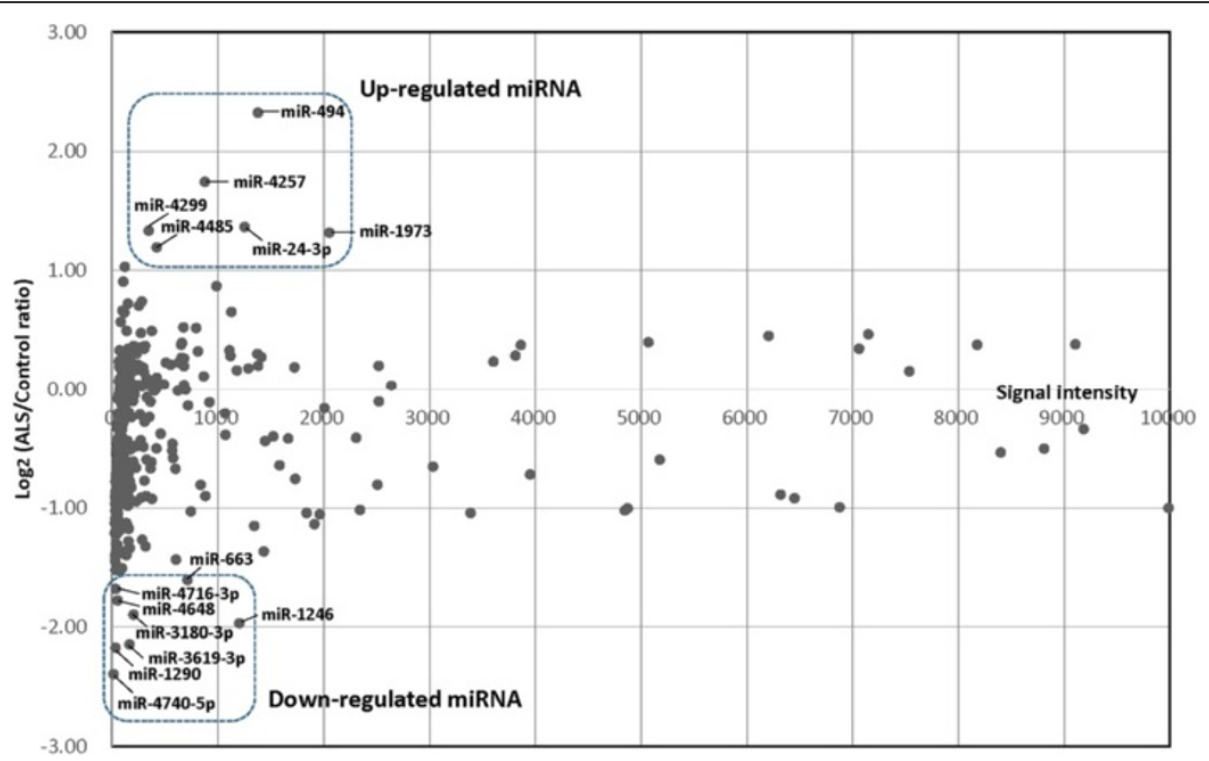

Figure 2 Scatter plot of all 364 miRNAs comparing signal intensity (X-axis) versus $\log _{2}$ fold-change of amyotrophic lateral sclerosis (ALS)/control ratio (Y-axis). Based on the size of variation, 6 up-regulated and 8 down-regulated miRNAs were selected in ALS. 
Top 50 candidate target genes of each of the 8 downregulated miRNAs in ALS were also selected. Of the 400 target candidates identified for each of the $8 \mathrm{miR}$ NAs, there was an overlap of 34 genes (Additional file 3: Table S3). These 34 genes have been reported to play a role in neurogenesis (ONECUT2 [69], KDM5A [70], NAT8L [71], NFIX [72]), mitochondrial regulation (IBA57 [66]) and autophagy (PRLA [73], SNCB [74], SOGA1 [54]). In addition, miR-3180-3p showed the most matching frequency (14 overlapped in 50 targets) in downregulated miRNAs.

It is important to note that 3 genes (IBA57, RAB3B and $S O G A 1)$ were identified as candidate target genes of both up-regulated and down-regulated miRNAs (Additional file 2: Table S2, Additional file 3: Table S3). IBA57 is known to be involved in the biosynthesis of mitochondrial [4Fe-4S] proteins [66]. Mutation of IBA57 causes severe myopathy and encephalopathy [66]. Rab3B is a synaptic vesicle protein that interacts with the Rab3interacting molecule isoforms as effector proteins in a GTP-dependent manner [64]. The search for an inhibitor of autophagy in the adiponectin signaling pathway led to the discovery of the Suppressor of Glucose from Autophagy (SOGA) [54]. These findings suggest that mitochondrial regulation, synaptic transmission and autophagy may be affected in ALS. Considering that the expression level of up-regulated miRNAs is higher than that of down-regulated miRNAs (Figure 2), these 3 genes may be down-regulated in the motor cortex of ALS.

\section{Gene ontology analysis of predicted target genes for disease-specific miRNAs}

A total of 300 candidates for 6 up-regulated miRNAs and 400 candidates for 8 down-regulated miRNAs were nominated as targets for gene ontology enrichment analysis (biological process). Additional file 4: Table S4 (A, B) shows top $10 \mathrm{GO}$ terms with MetaCore analysis and Additional file 4: Table S4 (C, D) shows top 10 GO terms with GOC analysis for standard GO terms. Two GO analyses suggested essentially similar biological process in upregulated and down-regulated miRNA target genes.

The biological processes in ALS altered by these target genes were shown to be related to protein transport, synaptic vesicle-mediated transport, and localization for up-regulated miRNAs and nervous system development for down-regulated miRNAs, as shown in Additional file 4: Table S4.

\section{Decrease of AMBRA1 immunoreactivity in ALS}

Since SOGA1 was identified as one of the overlapped target genes predicted by 6 up-regulated and 8 downregulated miRNAs, we hypothesized that alteration of autophagy is involved in the disease process of ALS. This may be supported by the findings that abnormal autophagy is involved in various neurodegenerative disorders, including ALS [75-79]. Therefore, we evaluated the protein expression levels of autophagy-related genes such as AMBRA1 [55], Beclin 1 [56], ULK1 [57] and ULK2 [57] by immunohistochemical examination of FFPE tissue.

In specimens from normal control subjects, antiAMBRA1 antibody strongly immunolabeled the cytoplasm of upper and lower motor neurons in a diffuse granular pattern (Figure 3A-C), consistent with a previous study [80]. In ALS, AMBRA1 immunoreactivity was decreased in the majority of spinal anterior horn cells (Figure 3D-F), but not in the motor cortex (data not shown), in comparison with controls.

Semi-quantitative analysis of normal controls showed that $30.2 \%$ of anterior horn cells were moderately or intensely immunolabeled, $48.5 \%$ were weakly immunolabeled, and $21.3 \%$ were unstained (Figure 4). Similarly, in diseased controls, $20 \%$ of anterior horn cells were moderately or intensely immunolabeled and $33.7 \%$ were weakly immunolabeled (Figure 4). The differences in staining intensity between normal and diseased controls were not statistically significant. In ALS, a small proportion of anterior horn cells (5.2\%) showed moderate or intense immunoreactivity, whereas the majority (83.5\%) were unstained (Figure 4). The differences in staining intensity between normal control and ALS cases and between diseased control and ALS cases were significant.

Immunoreactivity for Beclin 1, ULK1 and ULK2 was observed in the neuronal cytoplasm in normal controls. No significant difference was found in the staining intensity of these proteins between ALS and normal controls (data not shown).

\section{Discussion}

It has been reported that the formalin fixation and paraffin embedding process results in a marked reduction of detectable mRNA [81]. This process causes enzymatic degradation and chemical modification of RNA giving rise to cross-links with proteins and making RNA extraction difficult [52]. Therefore, a digestion step with proteinase $\mathrm{K}$ is required to eliminate cross-links and facilitate RNA extraction from FFPE samples [52]. The longer an RNA molecule is, the more likely cross-links will remain after proteinase $\mathrm{K}$ digestion, hence small RNA molecules will be easier to extract from FFPE samples and fragments larger than $200 \mathrm{nt}$ will be harder to recover from FFPE samples. In addition, electrophoretic profiles of total RNA from frozen samples show three characteristic peaks: $4080 \mathrm{nt}, 90 \mathrm{nt}$ and $150 \mathrm{nt}$, probably corresponding to tRNAs, rRNAs and snoRNAs, respectively. On the other hand, FFPE sample shows an accumulation of RNA fragments smaller than $200 \mathrm{nt}$ [82]. These findings suggest that the amount of total RNA that can be extracted from a FFPE tissue sample is 

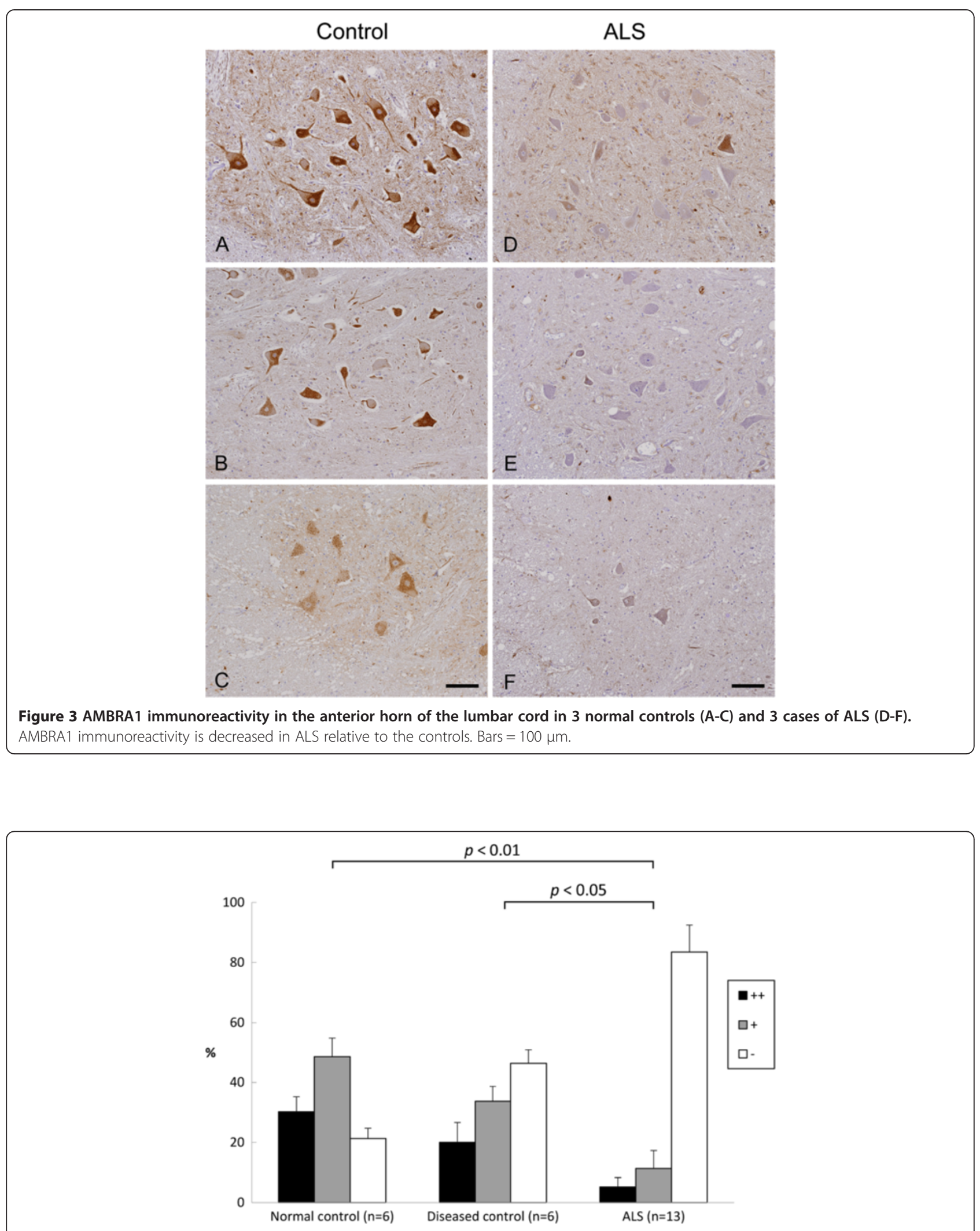

Figure 4 AMBRA1 immunoreactivity in anterior horn cells from normal and diseased controls and patients with ALS. The proportions of neurons showing intense/moderate (++, black column), weak (+, gray column), or no immunostaining for AMBRA1 ( - , white column) relative to the total number of neurons in the anterior horn are indicated. 
only a fraction of what can be extracted from its corresponding frozen tissue [81].

Although the number of subjects was small, we demonstrated for the first time that miRNAs extracted from FFPE samples of postmortem brain tissue from patients with neurodegenerative disorder (ALS) and neurologically normal controls were relatively well preserved; 12 of 26 samples (46.2\%), for which the longest storage period was more than 7 years, provided RNA of sufficient quality. Thus, miRNAs appear to be relatively stable in FFPE samples, even those from postmortem specimens. It has been suggested that miRNAs are too small to be degraded [83]. However, this hypothesis has not been supported by any reported data. It is now known that active, mature miRNAs are processed and function via binding to Argonaute family proteins $[84,85]$. These proteinmiRNA complexes may protect the functional population of miRNA from degradation, especially during the process of formalin fixation and storage in paraffin [49]. Peir-Chova et al. [82] have shown that the quantity of miRNAs from FFPE samples was higher than that obtained from frozen samples, since degradation of total RNA can produce fragments in the small RNA size range that could cause an overestimation in the proportion of its small sized fragments.

ALS is characterized by loss of upper and lower motor neurons. TDP-43 is now known to be a major component of ubiquitinated inclusions in ALS and frontotemporal lobar degeneration with ubiquitinated inclusions (FTLD-U, since renamed FTLD-TDP) [86,87]. Thus, these neurodegenerative disorders comprise a new disease concept: TDP-43 proteinopathy. Up- or down-regulated miRNAs in ALS in the present study and previously reported results are shown in Additional file 5: Table S5. Williams et al. [36] compared miRNA expression in skeletal muscle of normal and ALS model mice (G93A-SOD1 transgenic mice) and demonstrated that miR-206, a skeletal muscle-specific miRNA in humans and mice, delays disease progression in SOD1 transgenic mice. miR-206 is up-regulated in the skeletal muscle of ALS patients [32]. Shioya et al. [19] studied the miRNA expression profile in frozen samples of frontal cortex from three ALS patients using microarray analysis and found that miR-29a, miR$29 \mathrm{~b}$ and miR-338-3p were up-regulated. Up-regulation of miR-29b has also been reported in skeletal muscle of ALS patients [35]. De Felice et al. [33] evaluated miRNA expression in leukocytes obtained from ALS patients and healthy controls and demonstrated that miR-338-3p was also up-regulated in ALS. Seven miRNAs (miR-451, miR1275, miR-328, miR-638, miR-149, miR-665 and miR-583) were also down-regulated in ALS. Importantly, in our present study, three miRNAs (miR-29a, miR-29b and miR-338-3p) were also up-regulated and four miRNAs (miR-328, miR-451, miR-638 and miR-665) were down- regulated in FFPE samples of the motor cortex in ALS. Recently, De Felice et al. [34] further demonstrated that miR-338-3p was over-expressed in leukocytes, serum, CSF and frozen samples of spinal cord in patients with ALS, and that miR-338-3p expression in leukocytes was correlated with disease duration, suggesting that miR-338-3p may be a relevant clinical biomarker of ALS. It is likely that some miRNAs are systemically dysregulated in ALS and that miRNAs remain stable even in FFPE postmortem samples that have been stored for a long period.

We further demonstrated that AMBRA1 was significantly down-regulated in the lower motor neurons in ALS. This is in line with the results of our miRNA analysis that AMBRA1 is most possibly regulated by miR24-3p according to miRmap prediction (the rank 1 in canonical miRNAs of miRmap score $=97.37$ ) and that miR-24-3p is one of the highly up-regulated miRNAs in ALS (Additional file 1: Table S1). AMBRA1 is widely expressed in neurons in the normal mouse brain and is localized to the endoplasmic reticulum, perinuclear cisternae and outer mitochondrial membrane [80]. AMBRA1 interacts with Beclin 1, promoting its binding to lipid kinase Vps34, thus mediating autophagosome nucleation [55]. AMBRA1 is also known to be a Parkin-binding protein involved in mitophagy [88]. Abnormal autophagy is involved in various neurodegenerative disorders, including Alzheimer s disease [75,76], Parkinson s disease [78], multiple system atrophy [79] and ALS [77]. A recent study has shown that administration of rapamycin, an MTORdependent autophagy activator, ameliorates neuronal degeneration in FTLD-TDP model mice [89]. By contrast, rapamycin also aggravates neuronal death in a mouse model of ALS [90]. Thus, induction or repression of autophagy should be taken into account when considering novel therapeutic approaches for TDP-43 proteinopathy.

\section{Conclusion}

In conclusion, we have utilized FFPE brain samples from postmortem cases of ALS and neurologically normal controls and found that miRNAs extracted from these samples were relatively well preserved. Although further studies with a larger sample size are necessary, it is likely that archived FFPE postmortem samples can be a valuable source for miRNA profiling in neurodegenerative disorders.

\section{Additional files}

Additional file 1: Table S1. Top 20 microRNAs up- or down-regulated in the motor cortex in ALS.

Additional file 2: Table S2. Predicted target genes for ALS-specific up-regulated miRNAs identified by miRmap web-based open source software. 
Additional file 3: Table S3. Predicted target genes for ALS-specific down-regulated miRNAs identified by miRmap web-based open source software.

Additional file 4: Table S4. Gene ontology enrichment analysis (bilogical process) of predicted target genes for disease-specific miRNAs.

Additional file 5: Table S5. Summary of up- or down-regulated miRNAs in ALS.

\section{Competing interests}

The authors declare that they have no competing interests.

\section{Authors contributions}

$J U, \mathrm{HS}$ and KW managed the study and were principally responsible for writing. FM, AK, HT and KW performed the neuropathological observation and evaluation. JU performed bioinformatics analysis. HS and KW supervised whole process of the study. All authors read and approved the final manuscript.

\section{Acknowledgements}

The authors wish to express their gratitude to M. Nakata, A. Ono and Y. Hama for technical assistance.

\section{Funding}

This work was supported by JSPS KAKENHI Grant Number 26430049 (F.M.) and 24300131 (K.W.), a Grant from Japan Science and Technology Program (AS2314204F) (H.S., K.W.), a Grant for Hirosaki University Institutional Research (K.W.), the Collaborative Research Project (2014 2508) of the Brain Research Institute, Niigata University (F.M.), Grants-in-Aid for Research on rare and intractable diseases, the Research Committee on Establishment of Nove Treatments for Amyotrophic Lateral Sclerosis (H.S.), the Research Committee for Ataxic Disease (H.S., K.W.) and the Research Committee of CNS Degenerative Diseases (H.S.) from the Ministry of Health, Labour and Welfare, Japan, and an Intramural Research Grant (24 5) for Neurological and Psychiatric Disorders of NCNP (K.W.).

\section{Author details}

${ }^{1}$ Department of Neuropathology, Institute of Brain Science, Hirosaki University Graduate School of Medicine, 5 Zaifu-cho, Hirosaki 036-8562, Japan. ${ }^{2}$ Department of Pathological Neuroscience, Center for Bioresource-based Researches, Brain Research Institute, University of Niigata, Niigata, Japan. ${ }^{3}$ Department of Pathology, Brain Research Institute, University of Niigata, Niigata, Japan. ${ }^{4}$ Department of Neurology, Hokkaido University Graduate School of Medicine, Sapporo, Japan.

\section{Received: 30 October 2014 Accepted: 1 December 2014} Published online: 14 December 2014

\section{References}

1. Bartel DP (2004) MicroRNAs: genomics, biogenesis, mechanism, and function. Cell 116(2):281 297

2. Esquela-Kerscher A, Slack FJ (2006) Oncomirs - microRNAs with a role in cancer. Nat Rev Cancer 6(4):259 269

3. Lewis BP, Burge CB, Bartel DP (2005) Conserved seed pairing, often flanked by adenosines, indicates that thousands of human genes are microRNA targets. Cell 120(1):15 20

4. Ambros $V$ (2004) The functions of animal microRNAs. Nature 431(7006):350 355

5. Ma L, Weinberg RA (2008) Micromanagers of malignancy: role of microRNAs in regulating metastasis. Trends Genet 24(9):448 456

6. Cogswell JP, Ward J, Taylor IA, Waters M, Shi Y, Cannon B, Kelnar K, Kemppainen J, Brown D, Chen C, Prinjha RK, Richardson JC, Saunders AM, Roses AD, Richards CA (2008) Identification of miRNA changes in Alzheimer s disease brain and CSF yields putative biomarkers and insights into disease pathways. J Alzheimers Dis 14(1):27 41

7. Cui JG, Li YY, Zhao Y, Bhattacharjee S, Lukiw WJ (2010) Differential regulation of interleukin-1 receptor-associated kinase-1 (IRAK-1) and IRAK-2 by microRNA-146a and NF-KB in stressed human astroglial cells and in Alzheimer disease. J Biol Chem 285(50):38951 38960

8. Faghihi MA, Zhang $M$, Huang J, Modarresi F, Van der Brug MP, Nalls MA, Cookson MR, St-Laurent G 3rd, Wahlestedt C (2010) Evidence for natural antisense transcript-mediated inhibition of microRNA function. Genome Biol 11(5):R56
9. Geekiyanage $H$, Chan C (2011) MicroRNA-137/181c regulates serine palmitoyltransferase and in turn amyloid $\beta$, novel targets in sporadic Alzheimer s disease. J Neurosci 31(41):14820 14830

10. G?tz J, Ittner LM, F?ndrich M, Schonrock N (2008) Is tau aggregation toxic or protective: a sensible question in the absence of sensitive methods? J Alzheimer s Dis 14(4):423 429

11. H?bert SS, Horr? K, Nicola? L, Papadopoulou AS, Mandemakers W, Silahtaroglu AN, Kauppinen S, Delacourte A, De Strooper B (2008) Loss of microRNA cluster miR-29a/b-1 in sporadic Alzheimer s disease correlates with increased BACE1/ $\beta$-secretase expression. Proc Natl Acad Sci U S A 105(17):6415 6420

12. H?bert SS, Horr? K, Nicola? L, Bergmans B, Papadopoulou AS, Delacourte A, De Strooper B (2009) MicroRNA regulation of Alzheimer s amyloid precursor protein expression. Neurobiol Dis 33(3):422 428

13. H?bert SS, Papadopoulou AS, Smith P, Galas MC, Planel E, Silahtaroglu AN, Sergeant N, Bu?e L, De Strooper B (2010) Genetic ablation of Dicer in adult forebrain neurons results in abnormal tau hyperphosphorylation and neurodegeneration. Hum Mol Genet 19(20):3959 3969

14. Lukiw WJ (2007) Micro-RNA speciation in fetal, adult and Alzheimer s disease hippocampus. Neuroreport 18(3):297 300

15. Lukiw WJ, Zhao Y, Cui JG (2008) An NF-kB-sensitive micro RNA-146amediated inflammatory circuit in Alzheimer disease and in stressed human brain cells. J Biol Chem 283(46):31315 31322

16. Nunez-lglesias J, Liu CC, Morgan TE, Finch CE, Zhou XJ (2010) Joint genome-wide profiling of miRNA and mRNA expression in Alzheimer s disease cortex reveals altered miRNA regulation. PLoS One 5(2):e8898

17. Schratt G (2009) microRNAs at the synapse. Nat Rev Neurosci 10(12):842 849

18. Sethi P, Lukiw WJ (2009) Micro-RNA abundance and stability in human brain: specific alterations in Alzheimer s disease temporal lobe neocortex. Neurosci Lett 459(2):100 104

19. Shioya M, Obayashi S, Tabunoki H, Arima K, Saito Y, Ishida T, Satoh J (2010) Aberrant microRNA expression in the brains of neurodegenerative diseases: miR-29a decreased in Alzheimer disease brains targets neurone navigator 3. Neuropathol Appl Neurobiol 36(4):320 330

20. Smith P, Al Hashimi A, Girard J, Delay C, H?bert SS (2011) In vivo regulation of amyloid precursor protein neuronal splicing by microRNAs. J Neurochem 116(2):240 247

21. Wang WX, Rajeev BW, Stromberg AJ, Ren N, Tang G, Huang Q, Rigoutsos I, Nelson PT (2008) The expression of microRNA miR-107 decreases early in Alzheimer s disease and may accelerate disease progression through regulation of $\beta$-site amyloid precursor protein-cleaving enzyme 1. J Neurosci 28(5):1213 1223

22. Wang WX, Huang Q, Hu Y, Stromberg AJ, Nelson PT (2011) Patterns of microRNA expression in normal and early Alzheimer s disease human temporal cortex: white matter versus gray matter. Acta Neuropathol 121(2):193 205

23. Doxakis E (2010) Post-transcriptional regulation of a-synuclein expression by mir-7 and mir-153. J Biol Chem 285(17):12726 12734

24. Gehrke S, Imai Y, Sokol N, Lu B (2010) Pathogenic LRRK2 negatively regulates microRNA-mediated translational repression. Nature 466(7306):637 641

25. Junn E, Lee KW, Jeong BS, Chan TW, Im JY, Mouradian MM (2009) Repression of alpha-synuclein expression and toxicity by microRNA-7. Proc Natl Acad Sci U S A 106(31):13052 13057

26. Kim J, Inoue K, Ishii J, Vanti WB, Voronov SV, Murchison E, Hannon G, Abeliovich A (2007) A microRNA feedback circuit in midbrain dopamine neurons. Science 317(5842):1220 1224

27. Wang G, van der Walt JM, Mayhew G, Li YJ, Z? chner S, Scott WK, Martin ER Vance JM (2008) Variation in the miRNA-433 binding site of FGF20 confers risk for Parkinson disease by overexpression of a-synuclein. Am J Hum Genet 82(2):283 289

28. Johnson R, Zuccato C, Belyaev ND, Guest DJ, Cattaneo E, Buckley NJ (2008) A microRNA-based gene dysregulation pathway in Huntington s disease. Neurobiol Dis 29(3):438 445

29. Lee ST, Chu K, Im WS, Yoon HJ, Im JY, Park JE, Park KH, Jung KH, Lee SK, Kim M, Roh JK (2011) Altered microRNA regulation in Huntington s disease models. Exp Neurol 227(1):172 179

30. Packer AN, Xing Y, Harper SQ, Jones L, Davidson BL (2008) The bifunctional microRNA miR-9/miR-9* regulates REST and COREST and is downregulated in Huntington s disease. J Neurosci 28(53):14341 14346

31. Ubhi K, Rockenstein E, Kragh C, Inglis C, Spencer B, Michael S, Mante M, Adame A, Galasko D, Masliah E (2014) Widespread microRNA dysregulation 
in multiple system atrophy - disease-related alteration in miR-96. Eur J Neurosci 39(6):1026 1041

32. Bruneteau G, Simonet T, Bauch? S, Mandjee N, Malfatti E, Girard E, Tanguy ML, Behin A, Khiami F, Sariali E, Hell-Remy C, Salachas F, Pradat PF, Fournie E, Lacomblez L, Koenig J, Romero NB, Fontaine B, Meininger V, Schaeffer L, Hanta? D (2013) Muscle histone deacetylase 4 upregulation in amyotrophic lateral sclerosis: potential role in reinnervation ability and disease progression. Brain 136(Pt 8):2359 2368

33. De Felice B, Guida M, Guida M, Coppola C, De Mieri G, Cotrufo R (2012) A miRNA signature in leukocytes from sporadic amyotrophic lateral sclerosis. Gene 508(1):35 40

34. De Felice B, Annunziata A, Fiorentino G, Borra M, Biffali E, Coppola C, Cotrufo R, Brettschneider J, Giordana ML, Dalmay T, Wheeler G, D Alessandro R (2014) miR-338-3p is over-expressed in blood, CFS, serum and spinal cord from sporadic amyotrophic lateral sclerosis patients. Neurogenetics: Epub ahead of print

35. Russell AP, Wada S, Vergani L, Hock MB, Lamon S, L?ger B, Ushida T, Cartoni R, Wadley GD, Hespel P, Kralli A, Soraru G, Angelini C, Akimoto T (2012) Disruption of skeletal muscle mitochondrial network genes and miRNAs in amyotrophic lateral sclerosis. Neurobiol Dis 49C:107 117

36. Williams AH, Valdez G, Moresi V, Qi X, McAnally J, Elliott JL, Bassel-Duby R, Sanes JR, Olson EN (2009) MicroRNA-206 delays ALS progression and promotes regeneration of neuromuscular synapses in mice. Science 326 (5959):1549 1554

37. Freischmidt A, M?ller K, Ludolph AC, Weishaupt JH (2013) Systemic dysregulation of TDP-43 binding microRNAs in amyotrophic lateral sclerosis. Acta Neuropathol Commun 1(1):42

38. Margis R, Margis R, Rieder CR (2011) Identification of blood microRNAs associated to Parkinson s disease. J Biotechnol 152(3):96 101

39. Schipper HM, Maes OC, Chertkow HM, Wang E (2007) MicroRNA expression in Alzheimer blood mononuclear cells. Gene Regul Syst Bio 1:263 274

40. Doleshal M, Magotra AA, Choudhury B, Cannon BD, Labourier E, Szafranska AE (2008) Evaluation and validation of total RNA extraction methods for microRNA expression analyses in formalin-fixed, paraffin-embedded tissues. J Mol Diagn 10(3):203 211

41. Glud M, Klausen M, Gniadecki R, Rossing M, Hastrup N, Nielsen FC Drzewiecki KT (2009) MicroRNA expression in melanocytic nevi: the usefulness of formalin-fixed, paraffin-embedded material for miRNA microarray profiling. J Invest Dermatol 129(5):1219 1224

42. Lewis F, Maughan NJ, Smith V, Hillan K, Quirke P (2001) Unlocking the archive gene expression in paraffin-embedded tissue. J Pathol 195(1):66 71

43. Liu A, Tetzlaff MT, Vanbelle P, Elder D, Feldman M, Tobias JW, Sepulveda AR, Xu $X$ (2009) MicroRNA expression profiling outperforms mRNA expression profiling in formalin-fixed paraffin-embedded tissues. Int J Clin Exp Pathol 2(6):519 527

44. Szafranska AE, Davison TS, Shingara J, Doleshal M, Riggenbach JA, Morrison CD, Jewell S, Labourier E (2008) Accurate molecular characterization of formalin-fixed, paraffin-embedded tissues by microRNA expression profiling. J Mol Diagn 10(5):415 423

45. Xi Y, Nakajima G, Gavin E, Morris CG, Kudo K, Hayashi K, Ju J (2007) Systematic analysis of microRNA expression of RNA extracted from fresh frozen and formalin-fixed paraffin-embedded samples. RNA 13(10):1668 1674

46. Bing Z, Master SR, Tobias JW, Baldwin DA, Xu XW, Tomaszewski JE (2012) MicroRNA expression profiles of seminoma from paraffin-embedded formalin-fixed tissue. Virchows Arch 461(6):663 668

47. Chen L, Li Y, Fu Y, Peng J, Mo MH, Stamatakos M, Teal CB, Brem RF, Stojadinovic A, Grinkemeyer M, McCaffrey TA, Man YG, Fu SW (2013) Role of deregulated microRNAs in breast cancer progression using FFPE tissue. PLoS One 8(1):e54213

48. Ibusuki M, Fu P, Yamamoto S, Fujiwara S, Yamamoto Y, Honda Y, Iyama K, Iwase H (2013) Establishment of a standardized gene-expression analysis system using formalin-fixed, paraffin-embedded, breast cancer specimens. Breast Cancer 20(2):159 166

49. Lee TS, Jeon HW, Kim YB, Kim YA, Kim MA, Kang SB (2013) Aberrant microRNA expression in endometrial carcinoma using formalin-fixed paraffin-embedded (FFPE) tissues. PLoS One 8(12):e81421

50. Osawa S, Shimada Y, Sekine S, Okumura T, Nagata T, Fukuoka J, Tsukada K (2011) MicroRNA profiling of gastric cancer patients from formalin-fixed paraffin-embedded samples. Oncol Lett 2(4):613 619

51. Penland SK, Keku TO, Torrice C, He X, Krishnamurthy J, Hoadley KA, Woosley JT, Thomas NE, Perou CM, Sandler RS, Sharpless NE (2007) RNA expression analysis of formalin-fixed paraffin-embedded tumors. Lab Invest 87(4):383 391
52. Masuda N, Ohnishi T, Kawamoto S, Monden M, Okubo K (1999) Analysis of chemical modification of RNA from formalin-fixed samples and optimization of molecular biology applications for such samples. Nucleic Acids Res 27(22):4436 4443

53. Vejnar CE, Zdobnov EM (2012) miRmap: Comprehensive prediction of microRNA target repression strength. Nucleic Acids Res 40(22):11673 11683

54. Cowherd RB, Asmar MM, Alderman JM, Alderman EA, Garland AL, Busby WH, Bodnar WM, Rusyn I, Medoff BD, Tisch R, Mayer-Davis E, Swenberg JA, Zeisel SH, Combs TP (2010) Adiponectin lowers glucose production by increasing SOGA. Am J Pathol 177(4):1936 1945

55. Fimia GM, Stoykova A, Romagnoli A, Giunta L, Di Bartolomeo S, Nardacci R, Corazzari M, Fuoco C, Ucar A, Schwartz P, Gruss P, Piacentini M, Chowdhury K, Cecconi F (2007) Ambra1 regulates autophagy and development of the nervous system. Nature 447(7148):1121 1125

56. Zhong Y, Wang QJ, Li X, Yan Y, Backer JM, Chait BT, Heintz N, Yue Z (2009) Distinct regulation of autophagic activity by Atg14L and Rubicon associated with Beclin 1-phosphatidylinositol-3-kinase complex. Nat Cell Biol 11(4):468 476

57. Chan EY, Longatti A, McKnight NC, Tooze SA (2009) Kinase-inactivated ULK proteins inhibit autophagy via their conserved C-terminal domains using an Atg13-independent mechanism. Mol Cell Biol 29(1):157 171

58. Mori F, Tanji K, Miki Y, Wakabayashi K (2009) Decreased cystatin C immunoreactivity in spinal motor neurons and astrocytes in amyotrophic lateral sclerosis. J Neuropathol Exp Neurol 68(11):1200 1206

59. Groelz D, Sobin L, Branton P, Compton C, Wyrich R, Rainen L (2013) Nonformalin fixative versus formalin-fixed tissue: a comparison of histology and RNA quality. Exp Mol Pathol 94(1):188 194

60. von Ahlfen S, Missel A, Bendrat K, Schlumpberger M (2007) Determinants of RNA quality from FFPE samples. PLoS One 2(12):e1261

61. Shi X, Wallis AM, Gerard RD, Voelker KA, Grange RW, DePinho RA, Garry MG, Garry DJ (2012) Foxk1 promotes cell proliferation and represses myogenic differentiation by regulating Foxo4 and Mef2. J Cell Sci 125(Pt 22):5329 5337

62. Liu N, Nelson BR, Bezprozvannaya S, Shelton JM, Richardson JA, Bassel-Duby $\mathrm{R}$, Olson EN (2014) Requirement of MEF2A, C, and D for skeletal muscle regeneration. Proc Natl Acad Sci U S A 111(11):4109 4114

63. Humphries AC, Donnelly SK, Way M (2014) Cdc42 and the Rho GEF intersectin-1 collaborate with Nck to promote N-WASPdependent actin polymerisation. J Cell Sci 127(Pt 3):673 685

64. Tsetsenis T, Younts TJ, Chiu CQ, Kaeser PS, Castillo PE, S? dhof TC (2011) Rab3B protein is required for long-term depression of hippocampal inhibitory synapses and for normal reversal learning. Proc Natl Acad Sci U S A 108(34):14300 14305

65. Carta E, Chung SK, James VM, Robinson A, Gill JL, Remy N, Vanbellinghen JF, Drew CJ, Cagdas S, Cameron D, Cowan FM, Del Toro M, Graham GE, Manzur AY, Masri A, Rivera S, Scalais E, Shiang R, Sinclair K, Stuart CA, Tijssen MA, Wise G, Zuberi SM, Harvey K, Pearce BR, Topf M, Thomas RH, Supplisson S, Rees Ml, Harvey RJ (2012) Mutations in the GlyT2 gene (SLC6A5) are a second major cause of startle disease. J Biol Chem 287(34):28975 28985

66. Ajit Bolar N, Vanlander AV, Wilbrecht C, Van der Aa N, Smet J, De Paepe B, Vandeweyer G, Kooy F, Eyskens F, De Latter E, Delanghe G, Govaert P, Leroy JG, Loeys B, Lill R, Van Laer L, Van Coster R (2013) Mutation of the ironsulfur cluster assembly gene IBA57 causes severe myopathy and encephalopathy. Hum Mol Genet 22(13):2590 2602

67. Rowe GC, Jang C, Patten IS, Arany Z (2011) PGC-1 $\beta$ regulates angiogenesis in skeletal muscle. Am J Physiol Endocrinol Metab 301(1):E155 E163

68. Yang Q, She H, Gearing M, Colla E, Lee M, Shacka JJ, Mao Z (2009) Regulation of neuronal survival factor MEF2D by chaperone-mediated autophagy. Science 323(5910):124 127

69. Francius C, Clotman F (2010) Dynamic expression of the Onecut transcription factors HNF-6, OC-2 and OC-3 during spinal motor neuron development. Neuroscience 165(1):116 129

70. Shen E, Shulha H, Weng Z, Akbarian S (2004) Regulation of histone H3K4 methylation in brain development and disease. Philos Trans R Soc Lond B Biol Sci 369(1652). doi:10.1098/rstb.2013.0514

71. Toriumi K, Ikami M, Kondo M, Mouri A, Koseki T, Ibi D, Furukawa-Hibi Y, Nagai T, Mamiya T, Nitta A, Yamada K, Nabeshima T (2013) SHATI/NAT8L regulates neurite outgrowth via microtubule stabilization. J Neurosci Res 91(12):1525 1532

72. Wilczynska KM, Singh SK, Adams B, Bryan L, Rao RR, Valerie K, Wright S, Griswold-Prenner I, Kordula T (2009) Nuclear factor I isoforms regulate gene expression during the differentiation of human neural progenitors to astrocytes. Stem Cells 27(5):1173 1181 
73. Wei J, Fujita M, Nakai M, Waragai M, Watabe K, Akatsu H, Rockenstein E, Masliah E, Hashimoto M (2007) Enhanced lysosomal pathology caused by $\beta$-synuclein mutants linked to dementia with Lewy bodies. J Biol Chem 282 (39):28904 28914

74. Wen Y, Zand B, Ozpolat B, Szczepanski MJ, Lu C, Yuca E, Carroll AR, Alpay N, Bartholomeusz C, Tekedereli I, Kang Y, Rupaimoole R, Pecot CV, Dalton HJ, Hernandez A, Lokshin A, Lutgendorf SK, Liu J, Hittelman WN, Chen WY, Lopez-Berestein G, Szajnik M, Ueno NT, Coleman RL, Sood AK (2014) Antagonism of tumoral prolactin receptor promotes autophagy-related cell death. Cell Rep 7(2):488 500

75. Choi AM, Ryter SW, Levine B (2013) Autophagy in human health and disease. N Engl J Med 368(7):651 662

76. Nixon RA, Yang DS (2011) Autophagy failure in Alzheimer s disease locating the primary defect. Neurobiol Dis 43(1):38 45

77. Sasaki S (2011) Autophagy in spinal cord motor neurons in sporadic amyotrophic lateral sclerosis. J Neuropathol Exp Neurol 70(5):349 359

78. Tanji K, Mori F, Kakita A, Takahashi H, Wakabayashi K (2011) Alteration of autophagosomal proteins (LC3, GABARAP and GATE-16) in Lewy body disease. Neurobiol Dis 43(3):690 697

79. Tanji K, Odagiri S, Maruyama A, Mori F, Kakita A, Takahashi H, Wakabayashi K (2012) Alteration of autophagosomal proteins in multiple system atrophy. Neurobiol Dis 49C:190 198

80. Sepe S, Nardacci R, Fanelli F, Rosso P, Bernardi C, Cecconi F, Mastroberardino $P G$, Piacentini M, Moreno S (2014) Expression of Ambra1 in mouse brain during physiological and Alzheimer type aging. Neurobiol Aging 35(1):96 108

81. Abrahamsen HN, Steiniche T, Nexo E, Hamilton-Dutoit SJ, Sorensen BS (2003) Towards quantitative mRNA analysis in paraffin-embedded tissues using realtime reverse transcriptase-polymerase chain reaction: a methodological study on lymph nodes from melanoma patients. J Mol Diagn 5(1):34 41

82. Peir?-Chova L, Pe?a-Chilet M, L?pez-Guerrero JA, Garc?a-Gim?nez JL, Alonso-Yuste E, Burgues O, Lluch A, Ferrer-Lozano J, Ribas G (2013) High stability of microRNAs in tissue samples of compromised quality. Virchows Arch 463(6):765 774

83. Hui AB, Shi W, Boutros PC, Miller N, Pintilie M, Fyles T, McCready D, Wong D, Gerster K, Waldron L, Jurisica I, Penn LZ, Liu FF (2009) Robust global microRNA profiling with formalin-fixed paraffin-embedded breast cancer tissues. Lab Invest 89(5):597 606

84. Hutvagner G, Simard MJ (2008) Argonaute proteins: key players in RNA silencing. Nat Rev Mol Cell Biol 9(1):22 32

85. Mourelatos Z, Dostie J, Paushkin S, Sharma A, Charroux B, Abel L, Rappsilber J, Mann M, Dreyfuss G (2002) miRNPs: a novel class of ribonucleoproteins containing numerous microRNAs. Genes Dev 16(6):720 728

86. Arai T, Hasegawa M, Akiyama H, Ikeda K, Nonaka T, Mori H, Mann D, Tsuchiya K, Yoshida M, Hashizume Y, Oda T (2006) TDP-43 is a component of ubiquitinpositive tau-negative inclusions in frontotemporal lobar degeneration and amyotrophic lateral sclerosis. Biochem Biophys Res Commun 351(3):602 611

87. Neumann M, Sampathu DM, Kwong LK, Truax AC, Micsenyi MC, Chou TT, Bruce J, Schuck T, Grossman M, Clark CM, McCluskey LF, Miller BL, Masliah E, Mackenzie IR, Feldman H, Feiden W, Kretzschmar HA, Trojanowski JQ, Lee VM (2006) Ubiquitinated TDP-43 in frontotemporal lobar degeneration and amyotrophic lateral sclerosis. Science 314(5796):130 133

88. Van Humbeeck C, Cornelissen T, Hofkens H, Mandemakers W, Gevaert K, De Strooper B, Vandenberghe W (2011) Parkin interacts with Ambra1 to induce mitophagy. J Neurosci 31(28):10249 10261

89. Wang IF, Guo BS, Liu YC, Wu CC, Yang CH, Tsai KJ, Shen CK (2012) Autophagy activators rescue and alleviate pathogenesis of a mouse model with proteinopathies of the TAR DNA-binding protein 43. Proc Natl Acad Sci U S A 109(37):15024 15029

90. Zhang X, Li L, Chen S, Yang D, Wang Y, Zhang X, Wang Z, Le W (2011) Rapamycin treatment augments motor neuron degeneration in $\mathrm{SOD}^{\mathrm{G}}{ }^{\mathrm{G}} \mathrm{A}$ mouse model of amyotrophic lateral sclerosis. Autophagy 7(4):412 425

doi:10.1186/s40478-014-0173-z

Cite this article as: Wakabayashi et al: Analysis of microRNA from archived formalin-fixed paraffin-embedded specimens of amyotrophic lateral sclerosis. Acta Neuropathologica Communications 2014 2:173.

\section{Submit your next manuscript to BioMed Central and take full advantage of:}

凶Convenient online submission

$\otimes$ Thorough peer review

$\nabla$ No space constraints or color $\nabla$ gure charges

$\otimes I m m e d i a t e$ publication on acceptance

\Inclusion in PubMed, CAS, Scopus and Google Scholar

$\otimes$ Research which is freely available for redistribution

Submit your manuscript at www.biomedcentral.com/submit 